\title{
Associations of measured resting energy expenditure with predictive equations, NUTRIC score, and patient outcomes
}

\author{
Elham Sobhy ${ }^{1}$, Radwa Abdel Kader ${ }^{1}$, Alshaimaa Aboulfotouh², Mohammed Eshra ${ }^{3}$ and Mohamed Sayed ${ }^{14^{*}}$
}

\begin{abstract}
Background: Indirect calorimetry is the reference method for measuring resting energy expenditure (REE), but the necessary equipment and technical expertise are not always available. Meanwhile, the NUTrition Risk in the Critically ill (NUTRIC) scale is designed to identify patients who would benefit from nutrition therapy, but no data are available regarding the association of NUTRIC scores with REE. Several predictive formulas are available as alternatives to indirect calorimetry for calculation of energy requirements, but they have not been compared in a homogeneous group of critically ill patients. The purpose of the study is to examine the correlations between energy expenditure and NUTRIC scores or patient outcomes, and to compare measured REE with estimations of energy expenditure.

Methods: In this observational, prospective study, indirect calorimetry was performed on 50 mechanically ventilated patients. Energy expenditure was also estimated with the bodyweight-based, Faisy-Fagon, and PennState $P S U_{m}$ equations.

Results: REE was higher in patients who survived treatment than in those who died, and was positively correlated with length of stay and duration of ventilation. NUTRIC scores did not correlate with REE. The Faisy-Fagon equation overestimated expenditure, whereas PSU $\mathrm{m}$ was unbiased and accurate. Calculations based on $25 \mathrm{kcal} / \mathrm{kg}$ bodyweight/day overestimated expenditure, whereas $23 \mathrm{kcal} / \mathrm{kg} /$ day produced unbiased estimates with greater accuracy than $\mathrm{PSU}_{\mathrm{m}}$.
\end{abstract}

Conclusion: REE was positively associated with patient outcomes. Energy expenditure was accurately predicted by calculations of $23 \mathrm{kcal} / \mathrm{kg}$ bodyweight/day.

Keywords: REE, Indirect calorimetry, NUTRIC score, Weight-based formula, PSU ${ }_{m}$, Faisy-Fagon

\section{Background}

Critically ill patients are considered to be at a high nutritional risk in terms of their assessment scores or riskassessment outcomes [1]. Meeting caloric demand with adequate nutrition in such patients is related to positive outcomes. However, the optimal number of calories that should be prescribed to a critically ill patient is a matter of debate [2].

\footnotetext{
* Correspondence: dr.msh81@gmail.com

${ }^{1}$ Internal Medicine Department, KasrAlainy Cairo University, Cairo, Egypt

${ }^{4}$ Giza, Egypt

Full list of author information is available at the end of the article
}

The NUTrition Risk in the Critically ill (NUTRIC) scoring system is designed to quantify the risk of developing adverse events in critically ill patients, in whom risks might be modified by aggressive nutrition therapy. NUTRIC has been validated for the intensive-care unit (ICU) outcomes weaning from mechanical ventilation, length of stay (LOS) and mortality [3, 4]. However, there are no sufficient information on the relationship between NUTRIC scores and resting energy expenditure (REE) of critically ill patients, or on the relationship between REE and patient outcomes. 
Although indirect calorimetry is considered the gold standard for measurement of REE, the necessary equipment and technical expertise are not always available. Additionally, REE measurements should ideally be performed under standardized conditions that are not always feasible for patients in ICUs. As a consequence, predictive formulas that enable estimation of REE have been developed for use in ICUs [5].

The American College of Chest Physicians (ACCP) published a consensus statement in 1997 on nutrition in the critical-care setting, stating that an energy expenditure of $25 \mathrm{kcal} / \mathrm{kg}$ bodyweight/day is a reasonable standard for most patients [6]. However, subsequent testing of the equation in mixed surgical and medical patients has shown this figure to be biased, inaccurate, and imprecise [7].

The Penn State equation ( $\mathrm{PSU}_{\mathrm{m}}$ ) was developed using a mixed ICU population of 169 participants in Pennsylvania [8, 9]. The equation was found to be unbiased, accurate, and precise, although it was considered possible that the performance of the equation might vary according to the level of severity of the illness [7].

The Faisy-Fagon equation was presented in 2003 following its development from the analysis of data relating to 70 mechanically ventilated adult critical-care patients in France [10]. The equation was subsequently validated in a further 45 mechanically ventilated patients and found to be accurate and unbiased [11].

The 202 ventilated critical-care patients included in one of the largest studies to validate multiple energy expenditure equations [7] were a mix of medical and surgical patients with no recorded Acute Physiologic Assessment and Chronic Health Evaluation (APACHE) scores, and the method used for measurement of bodyweight was not clear.

Because of the existence of multiple predictive equations, it is necessary to compare the performance of these equations in specific groups, such as in medical patients in whom active metabolic weights are calculated. In this study, our aims were to correlate REE measured by indirect calorimetry with NUTRIC scores and patient outcomes, and to compare REE with calorie requirements estimated with the bodyweight-based, FaisyFagon, and $\mathrm{PSU}_{\mathrm{m}}$ equations.

\section{Methods}

This prospective, observational study was conducted in the Internal Medicine ICU over a period of 8 months from August 2016 to April 2017. All patients $\geq 18$ years old who were intubated and mechanically ventilated for $24 \mathrm{~h}$ and that were hemodynamically stable were considered for inclusion.

\section{Exclusion criteria}

Potential participants were excluded on the basis of any of the following factors: hemodynamic instability (introduction, dose modification, or withdrawal of inotropic drugs during the preceding $2 \mathrm{~h}$ ); respiratory instability (pulse oxygen saturation $<90 \%$, modification of ventilator settings during the preceding $2 \mathrm{~h}$ and signs of hyperventilation (respiratory rate > 35/min); bicarbonate infusion, digestive or renal losses of bicarbonate (diarrhea, ureterosigmoidostomy, use of acetazolamide) or the use of extracorporeal blood lines for dialysis; intravenous carbohydrate load $\geq 15 \mathrm{kcal} / \mathrm{kg} /$ day; and air leaks in the respiratory system or fraction of inspired oxygen $\left(\mathrm{FiO}_{2}\right) \geq 60 \%$.

\section{Methodology}

Eligible patients were thoroughly examined. Mid-upperarm circumference (MUAC) was measured to estimate body mass index (BMI) category. MUAC measurements were performed using the technique recommended by the British Association for Parenteral and Enteral Nutrition (BAPEN; Malnutrition Universal Screening Tool) in 2011. A MUAC $<23.5 \mathrm{~cm}$ was considered to indicate a $\mathrm{BMI}<20 \mathrm{~kg} / \mathrm{m}^{2}$, whereas a MUAC $>32.0 \mathrm{~cm}$ suggested BMI $>30 \mathrm{~kg} / \mathrm{m}^{2}$. Height was estimated from the length of the forearm (ulna), using tables provided by the Malnutrition Advisory Group of BAPEN [12].

Weight was calculated from estimated BMI and height. Notably, it has since been determined that weight is strongly correlated with MUAC in adults [13], with a very nearly linear relationship that is defined by the equation weight $(\mathrm{kg})=($ MUAC $[\mathrm{cm}] \times 4)-50$. This finding is supported by the median MUAC $(30 \mathrm{~cm})$ and weight $(70 \mathrm{~kg})$ values in our population.

Routine laboratory tests (complete blood count $[\mathrm{CBC}]$, liver function, kidney function, electrolytes, prothrombin time and lipid profile) were performed for all patients. The APACHE II score, Sequential Organ Failure Assessment (SOFA) score, and NUTRIC score were calculated for each patient.

\section{Estimation of caloric requirements}

Three equations were used for estimation of energy requirements (kcal/day) of each participant. For the weight-based formula, caloric requirement $=$ bodyweight $(\mathrm{kg}) \times 25[6]^{\cdot}$ For the Faisy-Fagon equation, caloric requirement $=(8 \times$ bodyweight $[\mathrm{kg}])+(14 \times$ height $[\mathrm{cm}])$ $+(32 \times$ minute ventilation $[1 / \mathrm{min}])+(94 \times$ body temperature $\left.\left[{ }^{\circ} \mathrm{C}\right]\right)-4834[10]^{\cdot}$ For the $\mathrm{PSU}_{\mathrm{m}}$ equation, caloric requirement $=(0.96 \times$ [value from Mifflin St Jeor equation $])+(167 \times$ [maximum body temperature in the previous $\left.\left.24 \mathrm{~h}\left({ }^{\circ} \mathrm{C}\right)\right]\right)+(31 \times$ minute ventilation $[1 / \mathrm{min}])$ - 6212. The Mifflin St Jeor equations were for men, (10 $\times$ weight $[\mathrm{kg}])+(6.25 \times$ height $[\mathrm{cm}])-(5 \times$ age [years $])$ 
+ 5; and for women, $(10 \times$ weight $[\mathrm{kg}])+(6.25 \times$ height $[\mathrm{cm}])-(5 \times$ age [years] $)-161$. For all equations, the weight used was the actual weight if the patient had a normal BMI (20-24.9), was overweight (BMI 25-29.9) or was underweight $(\mathrm{BMI}<18.5)$, or was the adjusted weight ([ideal body weight] $+0.25 \times$ ([actual weight] [ideal weight])) in obese patients (BMI $>30)$.

Indirect calorimetry was carried out using a metabolic module connected to Carescape R860 ventilator, with measurement of respiratory gas exchange for $30 \mathrm{~min}$, and calculation of REE by the modified Weir formula: $\left(5.5 \times \mathrm{VO}_{2}[\mathrm{ml} / \mathrm{min}]\right)+\left(1.76 \times \mathrm{VCO}_{2}[\mathrm{ml} / \mathrm{min}]\right)-(1.99$ $\times \mathrm{UN}$ (g/day), where $\mathrm{UN}$ is urea nitrogen excretion and is assumed to be $13 \mathrm{~g} /$ day for adults.

Our study was approved by the ethical committee.

\section{Statistical methods}

All data were entered into a Microsoft Excel spreadsheet. Data were coded and entered using the Statistical Package for the Social Sciences (SPSS) version 25. Comparisons between quantitative variables were performed using the unpaired $t$ test or the nonparametric MannWhitney test. Paired measurements for each patient were used in a paired $t$ test [14]. Correlations between quantitative variables were determined with the Spearman correlation coefficient [15]. $P$ values $<0.05$ were considered statistically significant.

\section{Results}

Fifty mechanically ventilated patients were included in the study, $56 \%$ of whom were female. Further demographic and descriptive data for the participants are shown in Table 1, and laboratory data are shown in Table 2.

We found significant correlation between REE determined by indirect calorimetry and caloric requirements calculated by each of the weight-based, Faisy-Fagon, and $\mathrm{PSU}_{\mathrm{m}}$ equations, with $P$ values of < $0.001,0.001$, and < 0.001 , respectively. However, there was also a significant difference between the measured REE and energy requirements estimated with the weight-based and Faisy-Fagon equations $(P<0.001$ and 0.012 , respectively). Energy expenditure estimation by $\mathrm{PSU}_{\mathrm{m}}$ showed no significant difference from measured REE.

\section{Bias statistics}

Bias was assessed by examining the 95\% confidence interval (CI) of the difference between the estimated and measured metabolic rates [16]. This method captures the tendency of an equation to underestimate or overestimate the true value. If the $95 \% \mathrm{CI}$ included zero, the equation was considered to be an unbiased estimator of the resting metabolic rate.

The precision of the predictive equations was assessed by examining the absolute differences between the estimated and measured resting metabolic rates as a percentage of the resting metabolic rates (also referred to as the root-mean-squared prediction error). Because this method uses the absolute difference, the canceling effect of underestimation and overestimation of the mean is eliminated. An estimate was considered precise if the root-mean- squared prediction error was $\leq 15 \%$ of the measurement.

Table 1 Demographic and descriptive data of the study participants

\begin{tabular}{lll}
\hline Characteristic & Mean \pm SD & Median (range) \\
\hline Age (years) & $56.44 \pm 19.21$ & $62.50(22-86)$ \\
Height (cm) & $169.36 \pm 5.51$ & $170.0(155-182)$ \\
Mid-upper arm circumference (cm) & $29.34 \pm 4.61$ & $30.00(21-41)$ \\
Bodyweight (kg) & $70.22 \pm 9.71$ & $70.00(53-114)$ \\
BMI $\left(\mathrm{kg} / \mathrm{m}^{2)}\right.$ & $27.29 \pm 5.08$ & $27.50(16-39)$ \\
Temperature $\left({ }^{\circ} \mathrm{C}\right)$ & $37.32 \pm 0.59$ & $37.00(37-39)$ \\
MV (L/min) & $9.26 \pm 2.57$ & $8.00(6-15)$ \\
APACHE II score & $16.60 \pm 7.45$ & $16.00(3-35)$ \\
SOFA score & $5.00 \pm 3.08$ & $5.00(0-12)$ \\
NUTRIC score & $2.92 \pm 2.19$ & $3.00(0-8)$ \\
Duration of ventilation (days) & $10.70 \pm 10.56$ & $6.50(2-40)$ \\
ICU stay (days) & $13.22 \pm 12.88$ & $8.00(2-50)$ \\
Caloric requirement (indirect calorimetry, kcal/day) & $1619.80 \pm 253.82$ & $1600.00(1100-2300)$ \\
Caloric requirement (weight-based $[25 \mathrm{kcal} / \mathrm{kg} /$ day], kcal/day) & $1755.90 \pm 242.48$ & $1750.00(1325-2300)$ \\
Caloric requirement (Faisy-Fagon equation, kcal/day) & $1866.72 \pm 215.81$ & $1876.00(974-2225)$ \\
Caloric requirement (PSU equation, kcal/day) & $1631.09 \pm 267.98$ & $1589.24(1199.24-2245.90)$ \\
\hline
\end{tabular}


Table 2 Laboratory data relating to the study participants

\begin{tabular}{ll}
\hline Variable & Mean \pm SD \\
\hline TLC & $14.57 \pm 6.94$ \\
Hemoglobin & $10.42 \pm 2.55$ \\
Platelet count & $200.44 \pm 111.14$ \\
PC & $73.74 \pm 17.15$ \\
International normalized ratio & $1.27 \pm 0.24$ \\
Urea & $97.32 \pm 68.68$ \\
Creatinine & $2.47 \pm 2.05$ \\
Na & $138.0 \pm 05.23$ \\
K & $4.31 \pm 0.82$ \\
ALT & $53.20 \pm 110.73$ \\
AST & $52.84 \pm 109.30$ \\
TB & $1.39 \pm 1.68$ \\
TLC & $14.57 \pm 6.94$ \\
Alb & $2.73 \pm 0.68$ \\
Ca & $8.07 \pm 1.27$ \\
Mg & $2.09 \pm 0.28$ \\
UA & $7.31 \pm 3.67$ \\
Phos & $4.58 \pm 1.80$ \\
LDL & $79.84 \pm 36.83$ \\
Chol & $141.54 \pm 47.84$ \\
TGs & $105.99 \pm 65.00$ \\
\hline
\end{tabular}

Accuracy was assessed as the percentage of estimates that fell within $10 \%$ of the measured value, and by the incidence of large errors (> 15\% above or below the measured rate).

Our results demonstrate that the Faisy-Fagon equation was biased towards overestimation of the caloric needs (95\% CI 171-323 kcal/day) and was also imprecise, with a root-mean-squared prediction error > 15\% (Table 3). By contrast, PSU $\mathrm{m}$ was unbiased (95\% CI - 48 to $71 \mathrm{kcal} /$ day) and precise.

Weight-based estimation at $25 \mathrm{kcal} / \mathrm{kg} /$ day was biased towards overestimation (95\% CI 64.7-207.5 kcal/day), had fairly low precision (95\% CI of prediction error 11.59-19.55\%), 40\% accuracy, and 38\% incidence of large errors. However, weight-based estimation at 23 $\mathrm{kcal} / \mathrm{kg} /$ day was unbiased, with greater precision and accuracy (Table 3), and with no significant difference between measured REE and calculated energy expenditure (data not shown).

Next, APACHE II scores were significantly negatively correlated with measured $\operatorname{REE}(P=0.031$; Table 4). NUTRIC scores were not significantly correlated with measured REE, although both NUTRIC scores and REE were positively correlated with ICU length of stay $(P=$ 0.011 and $P=0.015$, respectively) and duration of ventilation $(P=0.001$ and $P=0.012$, respectively). Patients who were successively weaned from ventilation and referred from the ICU had significantly lower NUTRIC scores $(P=0.025)$ than those who were not. Mean REE was significantly higher $(P=0.003)$ in patients who survived and were referred from the ICU $(1814.6 \pm 273.4$ $\mathrm{kcal} /$ day) than in those who died $(1564.9 \pm 222.1 \mathrm{kcal} /$ day) as shown in (Fig. 1). REE was also significantly correlated with both height $(P=0.01)$ and weight $(P<$ 0.001) (Table 4). Among the variables assessed by laboratory tests, platelet count, urea, creatinine, and phosphorus levels were significantly negatively correlated with REE (Table 4).

\section{Discussion}

In ventilated patients, calorimetry is often unavailable or inconvenient, making it important to derive equations that are predictive of REE. It is possible that results from these investigations can be extrapolated to nonintubated patients with similar degrees of illness in whom indirect calorimetry cannot be used.

The results indicated that in this population the FaisyFagon equation was biased towards overestimation, with a lower level of correlation with indirect calorimetry measurements than previously described [5]. Overestimation by this equation has also been described previously, including in groups of patients resembling our study population [7]. We also identified a lower level of precision with this equation than that determined in a previous study, with a 95\% CI of the root-mean-squared prediction errors of $13-19 \%$ in our population and 15$25 \%$ previously.

In the population, estimations with the $\mathrm{PSU}_{\mathrm{m}}$ equation showed significant correlation with measured REE, and this equation was unbiased and precise. In a previous

Table 3 Bias, accuracy, and precision of predictive equations relative to indirect calorimetry

\begin{tabular}{lllll}
\hline Equation & Bias $^{\mathbf{a}}$ (kcal/day) & Accuracy $^{\mathbf{b}}$ & Precision $^{\mathbf{c}}$ & Incidence of large errors $^{\mathbf{d}}$ \\
\hline Weight-based (23 kcal/kg/day) & $-73.35-64.60$ & $58.0 \%$ & $8.75-15.46 \%$ & $28 \%$ \\
PSU $_{\mathrm{m}}$ & $-48.12-70.71$ & $56.0 \%$ & $7.53-13.12 \%$ & $26.0 \%$ \\
Faisy-Fagon & $170.50-323.34$ & $30.0 \%$ & $15.43-25.25 \%$ & $54.0 \%$ \\
\hline
\end{tabular}

Bias assessed by the $95 \% \mathrm{Cl}$ of the difference between estimated and measured metabolic rates. An interval including 0 indicates no bias

${ }^{\mathrm{b}}$ Accuracy assessed as percentage of estimated values within $10 \%$ of corresponding measured values

'Precision assessed as $95 \% \mathrm{Cl}$ of root mean squared prediction errors considered precise if $\leq 15 \%$

dLarge errors were $15 \%$ above or below the measured value 
Table 4 Summary of parameters that correlated with indirect calorimetry

\begin{tabular}{lll}
\hline Parameter & Correlation coefficient & $\boldsymbol{P}$ value \\
\hline Height & 0.362 & 0.01 \\
Weight & 0.550 & 0.001 \\
APACHE II sCore & -0.306 & 0.031 \\
Phosphorus & -0.385 & 0.006 \\
Urea & -0.285 & 0.011 \\
Creatinine & -0.356 & 0.045 \\
Platelet count & -0.304 & 0.032 \\
ICU length of stay & 0.341 & 0.015 \\
Duration of ventilation & 0.917 & 0.012 \\
\hline
\end{tabular}

study, the findings were similar, but with higher accuracy $(67 \%)$ and lower incidence of large errors (13\%) than in our population (56\% and $26 \%$, respectively) [17]. This difference may be attributed in part to non-homogeneity among their study population, only $42 \%$ of whom were medical patients.

In our population, weight-based estimation of energy requirement at a level of $25 \mathrm{kcal} / \mathrm{kg} /$ day produced poor results, whereas a similar approach using a level of 23 $\mathrm{kcal} / \mathrm{kg} /$ day gave results that were comparable with those of $\mathrm{PSU}_{\mathrm{m}}$ in terms of bias, precision, accuracy, and incidence of large errors. This finding suggests that a simple weight-based equation could be used instead of the more complex $\mathrm{PSU}_{\mathrm{m}}$, in ventilated patients and in non-ventilated patients with a similar degree of illness.

Calculation of NUTRIC scores is a potential method for assessment of the nutritional needs of ICU patients, but in the population these scores did not show any correlation with measured REE. This finding is supported by previous results in which no difference was found between the outcomes of permissive underfeeding and standard enteral feeding in critically ill adults who were determined by NUTRIC scores to be either high or low

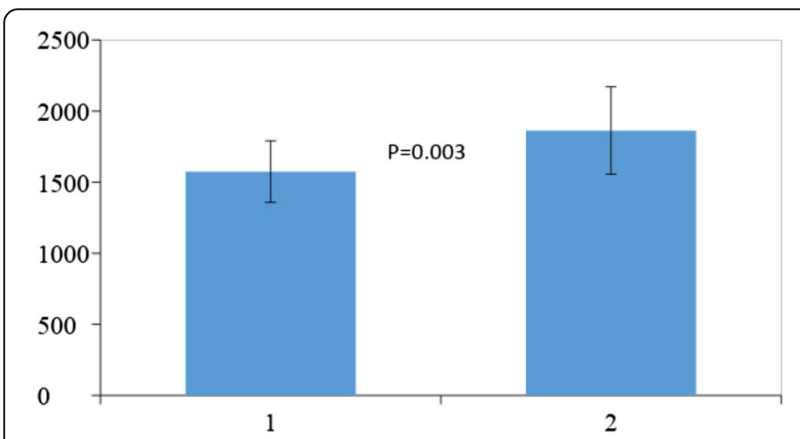

Fig. 1 Bar chart for comparison between measured resting metabolic rate of patients who were weaned from mechanical ventilator and referred and those who failed to be freed from the machine and died nutritional risk [17]. These results suggest that NUTRIC scores cannot be used to differentiate between patients who may or may not benefit from different caloric dosing.

The study found that REE was significantly higher in patients who survived and left the ICU than in those who died. REE was also positively correlated with length of stay and duration of ventilation, suggesting that high REE was associated with survival of acute insults, prolonging ventilation and hospital length of stay. Similar results were obtained previously [18], with identification of a significant difference $(P<0.001)$ in REE between survivors $(n=846$; mean REE $=1999.25 \pm$ $485.37 \mathrm{kcal} /$ day) and non-survivors $(n=325$; mean REE $=1842.50 \pm 497.48 \mathrm{kcal} /$ day $)$ at 60 days; however, no correlation was found between REE and 60-day mortality. These findings may be explained by the presence of ebb and flow phases. The ebb phase, which begins immediately after a traumatic shock, is characterized by a decrease in metabolic rate, decline in oxygen consumption and body temperature, and reduction in enzymatic activity. The flow phase follows and is marked by increased catabolism, with high oxygen consumption and elevation of energy expenditure [19].

Increased metabolism and catabolism in critically ill patients is considered an unavoidable shortcoming of severe illness, but it also represents an important survival mechanism, because the failure of the body to increase its metabolic rate leads to adverse outcomes. Decreased REE (a continuation of the ebb stage) may result from effects of sepsis and acute illness on mitochondri. In this model, patients who suffer less mitochondrial disturbance would have higher REEs and better outcomes than others with more severe injuries [20].

In the study population, the APACHE II score was negatively correlated with REE, suggesting that further studies could be conducted to determine whether there are any benefits to modulation of caloric intake according to patients' APACHE scores. The study did not find a significant correlation between age and REE, in agreement with previous findings, [10] which may be partially explained by the effects of stress counteracting agedependent reductions in metabolic rates. We found negative correlations between REE and several biochemical or cytological variables, including the level of phosphorus. This finding can be explained by mitochondrial injury. Phosphorus-containing compounds have important roles in cell structure, cellular metabolism, and regulation of subcellular processes; low phosphorus levels would therefore alter energy production [21]. In the recovery phase, increased physiological use of phosphorus leads to increased energy production and to reduction of systemic phosphorus levels, as occurs in refeeding syndrome. 
Notably, there were some limitations to the study. The sample size was limited by the requirement for metabolic stability for measurement of REE. In clinical practice, most ventilated patients briefly satisfy this criterion, thereby enabling energy requirement to be estimated with a predictive equation, but not to be measured with indirect calorimetry. The study also had some strengths-to the best of our knowledge, it was the first prospective, single-center study to correlate REE in ventilated patients with the NUTRIC score and with patient outcomes. Moreover, the study population was homogeneous and included only mechanically ventilated medical patients.

\section{Conclusion}

Weight-based caloric estimation is appealing because of its ease of use, applicability, and comparable or even superior accuracy compared with more sophisticated equations. Calculation of energy expenditure at values $<25$ $\mathrm{kcal} / \mathrm{kg} /$ day may be appropriate in patients with high APACHE II scores.

Notably, APACHE II scores were negatively correlated with REE, which could be helpful when calculating caloric needs.

REE was significantly higher in patients who were successfully weaned from ventilation and discharged alive than in those with worse outcomes. However, NUTRIC scores were not significantly correlated with REE and are unlikely to be useful for planning nutritional strategies for patients in the ICU.

\footnotetext{
Acknowledgements

The authors acknowledge subjects for their participation and cooperation in this study.
}

\begin{abstract}
Authors' contributions
RA participated in the concept and design of the study, is responsible for coordination and recruitment of participants, and helped in the clinical examination and data analysis. MS participated in the concept and design of the study and analysis of data, helped in the clinical examination, helped in applying the inclusion and exclusion criteria, helped in drafting the manuscript, and performed the statistical analysis. ES, AA, and ME participated in the concept and design of the study, participated in the clinical examination, and applied the inclusion and exclusion criteria. All authors have read and approved the final manuscript.
\end{abstract}

\section{Funding}

Not applicable

\section{Availability of data and materials}

The datasets used and/or analyzed during the current study are available from the corresponding author on reasonable request.

\section{Declarations}

\section{Ethics approval and consent to participate}

All procedures followed were in accordance with the ethical standards of the responsible committee on human experimentation (institutional and national) and with the Helsinki Declaration of 1975, as revised in 2008. Informed written consent was not obtained from all patients for being included in the study as they were mechanically ventilated and not fully conscious and our study was approved by the ethical committee of Cairo university. (the ethics committee reference number is I-171015 (April 2021).

\section{Consent for publication}

No personal data were used for publication.

\section{Competing interests}

The authors declare that they have no competing interests.

\section{Author details}

${ }^{1}$ Internal Medicine Department, KasrAlainy Cairo University, Cairo, Egypt. ${ }^{2}$ Neurology Department, KasrAlainy Cairo University, Cairo, Egypt. ${ }^{3}$ Physiology Department, KasrAlainy Cairo University, Cairo, Egypt. ${ }^{4}$ Giza, Egypt.

Received: 2 April 2021 Accepted: 26 June 2021

Published online: 18 October 2021

\section{References}

1. McClave SA, Martindale RG, Vanek WW, McCarthy M, Roberts P, Taylor B, Ochoa JB, Napolitano L, Cresci G, A.S.P.E.N. Board of Directors; American College of Critical Care Medicine; Society of Critical Care Medicine: Guidelines for the Provision and Assessment of Nutrition Support Therapy in the Adult Critically III Patient: Society of Critical Care Medicine (SCCM) and American Society for Parenteral and Enteral Nutrition (A.S.P.E.N.). JPEN J Parenter Enteral Nutr 2009, 33(3):277-316.

2. Stapleton RD, Jones N, Heyland DK (2007) Feeding critically ill patients: what is the optimal amount of energy? Crit Care Med. 35(Suppl 9):S535-S540. https://doi.org/10.1097/01.CCM.0000279204.24648.44

3. Kothandaramanujam RM, Arunkumar AS (2016) MON-LB266: assessing nutritional risk in critically ill mechanically ventilated patients-Subjective Global Assessment (SGA), Nutrition Risk in Critically III (NUTRIC) score or a combination? Clin Nutr. 35:S250-S251

4. Mendes R, Policarpo S, Fortuna P, Alves M, Virella D, Heyland DK, Portuguese NUTRIC Study Group (2017) Nutritional risk assessment and cultural validation of the modified NUTRIC score in critically ill patients-a multicenter prospective cohort study. J Crit Care 37:45-49. https://doi.org/1 0.1016/j.jcrc.2016.08.001

5. Savard JF, Faisy C, Lerolle N, et al. Validation of a predictive method for an accurate assessment of resting energy expenditure in medical mechanically ventilated patients- Crit Care Med 2008;36, No. 4.

6. Cerra FB, Benitez MR, Blackburn GL, Irwin RS, Jeejeebhoy K, Katz DP, Pingleton SK, Pomposelli J, Rombeau JL, Shronts E, Wolfe RR, Zaloga GP (1997) Applied nutrition in ICU patients: a consensus statement of the American College of Chest Physicians. Chest. 111(3):769-778. https://doi. org/10.1378/chest.111.3.769

7. Frankenfield DC, Coleman A, Alam S, Cooney RN (2009) Analysis of Estimation Methods for resting metabolic Rate in Critically III Adults. JPEN JParenter Enteral Nutr. 33(1):27-36. https://doi.org/10.1177/014 8607108322399

8. Yu E, Rimm E, Qi L, Rexrode K, Albert CM, Sun Q, Willett WC, Hu FB, Manson JE (2016) Diet, lifestyle, biomarkers, genetic factors, and risk of cardiovascular disease in the Nurses' Health Studies. Am. J. Public Health. 106(9):16161623. https://doi.org/10.2105/AJPH.2016.303316

9. Frankenfield D, Smith JS, Cooney RN (2004) Validation of 2 approaches to predicting resting metabolic rate in critically ill patients. JPEN J Parenter Enteral Nutr. 28(4):259-264. https://doi.org/10.1177/0148607104028004259

10. Faisy C, Guerot E, Diehl JL, Labrousse J, Fagon JY (2003) Assessment of resting energy expenditure in mechanically ventilated patients. Am J Clin Nutr. 78(2):241-249. https://doi.org/10.1093/ajcn/78.2.241

11. Savard JF, Faisy C, Lerolle N, Guerot E, Diehl JL, Fagon JY (2008) Validation of a predictive method for an accurate assessment of resting energy expenditure in medical mechanically ventilated patients. Crit care med 36(4):1175-1183. https://doi.org/10.1097/CCM.0b013e3181691502

12. Marinella MA (2003) The refeeding syndrome and hypophosphatemia. Nutr Rev 61: 320-323.

13. Cattermole GN, Graham CA, RainerTH. Mid-arm circumference can be used to estimate weight of adult and adolescent patients. Emerg Med J 2017;34: 231-236.

14. Chan YH.Biostatistics 102: Quantitative data - parametric \& non-parametric tests. Singapore Med J. 2003a;44(8): 391-96. 
15. Chan YH. Biostatistics 104: Correlational analysis. Singapore Med J. 2003b; 44(12) : 614-19.

16. Sheiner LB, Beal SL (1981) Some suggestions for measuring prediction performance. J Pharmacokinet Biopharm. 9(4):503-512. https://doi.org/10.1 007/BF01060893

17. Zusman O, Theilla M, Cohen J, Kagan I, Bendavid I, Singer P (2016) Resting energy expenditure, calorie and protein consumption in critically ill patients: a retrospective cohort study. Crit Care. 20(1):367. https://doi.org/10.1186/s13 054-016-1538-4

18. Cuthbertson DP (1982) The metabolic response to injury and other related explorations in the field of protein metabolism: an autobiographical account. Scott Med J. 27(2):158-171. https://doi.org/10.1177/003693308202 700210

19. Fink MP (2001) Cytopathic hypoxia. Mitochondrial dysfunction as mechanism contributing to organ dysfunction in sepsis. Crit Care Clin. 17(1): 219-237. https://doi.org/10.1016/50749-0704(05)70161-5

20. Arabi YM, Aldawood AS, Haddad SH, Al-Dorzi HM, Tamim HM, Jones G, Mehta S, Mclntyre L, Solaiman O, Sakkijha MH et al (2015) PermiT Trial Group. Permissive underfeeding or standard enteral feeding in critically ill adults. N Engl J Med 372(25):2398-2408. https://doi.org/10.1056/NEJMoa1 502826

21. Amanzadeh J, Reilly RF Jr (2006) Hypophosphatemia: an evidence-based approach to its clinical consequences and management. Nat clin pract nephrol. 2(3):136-148. https://doi.org/10.1038/ncpneph0124

\section{Publisher's Note}

Springer Nature remains neutral with regard to jurisdictional claims in published maps and institutional affiliations.

\section{Submit your manuscript to a SpringerOpen ${ }^{\circ}$ journal and benefit from:}

- Convenient online submission

- Rigorous peer review

- Open access: articles freely available online

- High visibility within the field

- Retaining the copyright to your article

Submit your next manuscript at $\boldsymbol{\nabla}$ springeropen.com 